\title{
Emergency versus elective ureteroscopic treatment of ureteral stones
}

\author{
Yousef S. Matani, MD, FRCS; Mohammed A. Al-Ghazo, MD, FRCS; Rami S. Al-Azab, MD; Osamah Bani Hani, MD; \\ Ibrahim F. Ghalayini, MD, FRCS; Ibrahim Bani Hani, MD, FRCS
}

King Abdullah University Hospital, Department of Surgery and Urology, Jordan University of Science and Technology, Faculty of Medicine, Irbid, Jordan

Cite as: Can Urol Assoc J 2013;7(7-8):e470-4. http://dx.doi.org/10.5489/cuaj.1402 Published online July 2, 2013.

\section{Abstract}

Introduction: This retrospective study investigates the role of the emergency ureteroscopic (URS) approach in the definitive treatment of ureteric stones.

Methods: We reviewed all patients admitted for ureteric stones from May 2003 to December 2010. Those who underwent URS stone treatment were selected and stratified into emergency (EMG) and elective groups (ELG). Emergency URS is defined as URS being performed within 24 hours of admission to the emergency room. The main indication for emergency treatment was refractory ureteric colic in spite of narcotic analgesia. Both groups were statistically compared in terms of their patient-, stone- and outcome-related variables. The overall success rate was defined by the clearance of the stone and/or presence of residual fragments $(<3 \mathrm{~mm})$ at the end of 4-week follow-up period.

Results: In total, 903 patients were suitable for analysis with 244 and 659 patients in the EMG and ELG, respectively. Age, sex and comorbidities were comparable in both groups. Average ages were $43.4 \pm 15.31$ and $45.6 \pm 13.24$ years among EMG and ELG, respectively. Stones had an average size of $0.92 \pm 0.49$ (in the EMG group) and $0.96 \pm 0.53 \mathrm{~cm}$ (in the ELG group). We found that $61.1 \%$ and $65.7 \%$ of stones were distally located in the EMG and ELG, respectively. EMG had a longer operative time $(69 \pm 21.03$ vs. $57 \pm 13.45$ minutes) with comparable average hospital stays (1.9 days). Intra-operative double-J stents or ureteric catheter insertion was noted in 72.5 and $67.7 \%$ of EMG and ELG, respectively. The overall complication rates were reported in $13.1 \%$ in EMG and $14.4 \%$ in ELG. A higher rate of ureteric injuries (early and late) was documented in the EMG group (7\% vs. 5.6\%). Most of these injuries were minor and manageable without additional procedure and/or general anesthesia. Success was achieved in $90.6 \%$ and $91.8 \%$ of the EMG and ELG groups, respectively.

Conclusion: With recent advances in technology, the growing trend toward one-stage definitive treatment, patient acceptability and rising concerns over financial aspects, emergency URS treatment of ureteric stones is evolving as a standard initial management option.

\section{Introduction}

Urinary stone disease is a common cause for office and emergency room referrals. The universal incidence of urinary tract stones is high, with a $4 \%$ to $15 \%$ rate worldwide. Ureteral stones account for $20 \%$ of urolithiasis, with about $70 \%$ of them distally located. ${ }^{1}$

Management of acute renal colic caused by ureteric stones has been described in current literature and guidelines. When drug therapy fails to resolve symptoms, the next step is to place a ureteric catheter, double-J stent or nephrostomy tube. ${ }^{2-4}$ These simple procedures can provide prompt symptom relief, and they are usually followed by ureteroscopic (URS) or shock wave lithotripsy (SWL), which are currently the main options for symptomatic ureteral stones. Although URS is a more invasive option than SWL, it has a better success rate, especially for mid- and distal ureteral stones. $^{7}$

Consensus appears to favour minimally invasive therapeutic procedures, but it is still debated whether SWL or URS should be the first-line treatment option for patients with ureteral stones. The recent developments of small-calibre semi-rigid and flexible deflectable ureteroscopes and of diminutive intracorporeal lithotripsy probes have made retrograde access to urinary calculi throughout the entire ureter more feasible and less risky. ${ }^{8,9}$

Although there is a growing interest in URS, there is little data available on the use of emergency URS to treat ureteral colic caused by ureteral stones. The emergency approach, within 24 to 48 hours of presentation to the emergency room, is both attractive and cost-effective. It is still being explored in the AUA and EUA stone treatment guidelines, which have emphasized the value of elective retrograde laser treatment of stones and discouraged the routine use of double-J stents in uncomplicated URS. ${ }^{2,3}$ Teichman, in his management algorithm, emphasized the value of temporary procedures, such as nephrostomy or double-J stenting. He highlighted the shift towards non-urgent pathways in handling urgent stone conditions. ${ }^{4}$ 
In this study, we present our experiences with emergency URS management of ureteral stones and compare them with the elective URS approach. Efficacy and safety will be compared.

\section{Methods}

From May 2003 to December 2010, the medical records of all patients with ureteral stones who were managed by URS at King Abdullah University Hospital were retrospectively reviewed. There were a total of 903 patients. Patients were divided into 2 groups: emergency (EMG) and elective (ELG) URS cases. We included 244 (27\%) EMG and 659 (73\%) ELG cases. The data were divided into patient-, stone- and outcome-related variables. Patient variables included age, sex and associated comorbidities; stone factors included the size and site of calculi along the ureter.

Among the EMG group, there were 184 males and 60 females $(75.4 \%$ vs. $24.6 \%)$; mean age $45.6 \pm 13.24$ years (range: $22-73)$. The ELG group included 508 males and 151 females ( $77 \%$ vs. $23 \%$ ); mean age $43.4 \pm 15.31$ years (range: 16-80). Emergency URS with lithotripsy for ureteral calculi was performed within 24 hours of admission to the emergency room. All the patients consented before the procedure. We received approval from both the university and hospital Institutional Review Boards. To be included in the study, patients had to have presented to the emergency room for the first time, had acute renal colic resistant to medical therapy, no evidence of urinary tract infection, no acute renal failure and stone size above $0.7 \mathrm{~cm}$. Children, pregnant women and patients with radiolucent stones were excluded. The main diagnostic radiological investigations were kidney, ureter and bladder (KUB) and non-enhanced spiral computed tomography (CT). Proximal and distal ureteral stones were defined as those above and below the pelvic brim, respectively, as suggested by Hollenback and colleagues, ${ }^{10}$ while mid-ureteral stones were located over the sacral bone. In total, $149(61.1 \%)$ and $433(65.7 \%)$ patients had distal ureteric stones in the EMG and ELG groups, respectively.

URS was performed under general or spinal anesthesia with a 7.5 Fr semirigid ureteroscope (Wolf) or $8 \mathrm{Fr}$ (Karl Storz Endoskope, Tuttlingen, Germany) with the aid of fluoroscopy.

Intracorporeal lithotripsy, when necessary, was performed with the Swiss lithoclast (EMS Medical, Nyon, Switzerland). Stone fragments were removed with stone graspers, although small fragments $(<0.3 \mathrm{~cm})$ were left to pass spontaneously. At the end of the procedure, an indwelling ureteric stent/ catheter was inserted in $177(72.5 \%)$ and $446(67.7 \%)$ of the EMG and ELG, respectively. The catheter was inserted in cases with multiple stone fragments $(<3 \mathrm{~mm})$ and was removed within 24 hours. A double-J stent was inserted if there was significant ureteral wall trauma, edema at the stone impaction site, suspected or demonstrated ureteral perforation, and if the stone migrated to the kidney. Before discharge, patients underwent a plain X-ray to assess the initial stone-free status (stone fragments $<0.3 \mathrm{~cm}$ were considered successful) and to confirm the correct stent position for those with a double-J stent. The average operative time and hospital stay were also calculated. All patients, in both groups, received a single $1 \mathrm{~g}$ intravenous ceftriaxone sodium infusion 1 to 2 hours before the procedure.

Outcome measurement was based on the frequency of stenting, failure proportions and overall complication rates. Stone clearance rate was determined initially and at the end of the 4-week follow-up period. Success was defined by the absence of stone (visual/radiological) and/or presence of clinically insignificant fragments $(<0.3 \mathrm{~cm})$. Overall stonefree rate denotes the disappearance of the offending stone at the end of 4 weeks postoperatively. Morbidity, other than those commonly associated with ureteric stents, included unusual postoperative pain requiring analgesia, gross hematuria lasting for $>72$ hours, fever/urosepsis, ureteric perforation, avulsion, false passage and stricture.

The chi-square, Kruskal-Wallis and Fisher's exact test were used to compare group variables. The two-tailed t-test was used to assess the significance of differences between continuous variables. The analysis was performed by using SPSS v.16.0 (SPSS Inc., Chicago, IL), and statistical significance was $p<0.05$.

\section{Results}

Of the 903 patients, 244 (27\%) were EMG and 659 (73\%) of ELG (Table 1). There was no significant difference regarding age $(45.6 \pm 13.24$ EMG vs. $43.4 \pm 15.31$ ELG $p=0.073)$ and sex (0.674) of both groups. The distribution curve was shifted more to the left, reflecting the younger Jordanian population. ${ }^{11}$ The associated medical conditions were crudely quantified for the sake of comparison by using an index. This was calculated by assigning 1 point to each condition (e.g., hypertension) then adding all the patients' scores and getting the average. The average comorbidity index was $9.2 \pm 3.4$ and $10.6 \pm 5.12$ for the EMG and ELG, respectively ( $p=0.093)$. This finding grossly implies comparable medical fitness.

Stones in ELG were, on average, larger $(0.96 \pm 0.53 \mathrm{~cm})$ than their counterparts in EMG $(0.92 \pm 3.4 \mathrm{~cm})$; the difference was, however, not statistically relevant $(p=0.056)$. A significantly higher percentage of patients in the EMG had mid-ureteric stones $(p=0.031)$; whereas the reverse was noted for distal ureteric stones (61.1 vs. $65.7 \%, p=0.041)$. The procedure time was, insignificantly, longer in the emergency cases. Most procedures took about 60 minutes, with $69 \pm 21.03$ and $57 \pm 13.45$ recorded in the EMG and ELG, respectively $(p=0.061)$. The hospital stay was about 2 days 
Table 1. Patient and stone characteristics

\begin{tabular}{lccc}
\hline Variable & $\begin{array}{c}\text { EMG* } \\
(\mathbf{n = 2 4 4 )}\end{array}$ & $\begin{array}{c}\text { ELG** } \\
(\mathbf{n = 6 5 9 )}\end{array}$ & $\boldsymbol{p}$ value \\
\hline Age (yr) & $45.6 \pm 13.24$ & $43.4 \pm 15.31$ & 0.073 \\
Sex & & & 0.674 \\
$\quad$ Male & $184(75.4)$ & $508(77)$ & \\
$\quad$ Female & $60(24.6)$ & $151(23)$ & \\
Average comorbidity factor & $9.2 \pm 3.4$ & $10.6 \pm 5.12$ & 0.093 \\
Stone size & $0.92 \pm 0.49$ & $0.96 \pm 0.53$ & 0.056 \\
Stone location: & & & \\
$\quad$ Upper ureter & $49(20.1)$ & $147(22.3)$ & 0.053 \\
$\quad$ Mid-ureter & $46(18.8)$ & $79(12)$ & 0.031 \\
$\quad$ Lower ureter & $149(61.1)$ & $433(65.7)$ & 0.041 \\
Operative time (min) & $69 \pm 21.03$ & $57 \pm 13.45$ & 0.061 \\
Hospital stay (days) & $1.9 \pm 1.34$ & $1.9 \pm 1.02$ & 0.413 \\
Follow-up period (weeks) & 4 & 4 & - \\
\hline
\end{tabular}

Values are presented as mean \pm standard deviation or number $(\%) ; p<0.05$ is significant. *Emergency group underwent ureteroscopy within 24 hours of admission to an emergency room; **Elective group underwent ureteroscopy more than 24 hours of admission to an emergency room.

and comparable in both groups $(p=0.413)$. The follow-up period was 4 weeks from the procedure date.

The procedure was standardized with little inter-operator variations in anesthesia, prophylaxis, indication, technique, stenting, postoperative protocol and level of experience. Surgeon experience and technology were, therefore, not compared in our analysis.

Outcome assessment included frequency of stenting, failures and complications. The concept of morbidity in surgical procedures was defined in accordance with the ClavienDindo classification (Table 2). ${ }^{12}$

Overall ureteric intubation rates using catheters or double-J stents were $72.5 \%$ in the EMG and $67.7 \%$ in the ELG $(p=0.043)$. This significant difference was not substantiated upon considering double-J stenting rates alone $(p=0.063)$.

Initial failure rate was $21.3 \%$ in the EMG as compared to $11.1 \%$ in ELG $(p=0.031)$. This difference was very significant. The overall stone-free rate at the end of the 4 weeks was statistically comparable (90.6 EMG vs. 91.8\% ELG, $p<0.238)$.

The overall complication rates in EMG and ELG were 13.1 and $14.4 \%$, respectively $(p=0.044)$. The commonest morbidity was severe postoperative pain requiring narcotic analgesics, delay in discharge and/or re-admission. These were not found significantly different $(p=0.053)$. Prolonged gross hematuria $>72$ hours postoperatively was more frequent in the ELG group (2.6 vs. 1.6, $p=0.031)$. The hematuria was associated with either URS procedure and/or ureteric intubation. Urinary tract infection, additionally, was more prevalent in the ELG group $(p=0.042)$.

Overall ureteric injuries were documented more in the EMG group, yet these numbers were not statistically significant ( 7 vs. $5.6 \%, p=0.057$ ). Perforations were recorded in $3.2 \%$ among the ELG procedures compared to $2.9 \%$
Table 2. Outcome variables in both groups

\begin{tabular}{lccc}
\hline Variable & $\begin{array}{c}\text { EMG* } \\
(\mathbf{n = 2 4 4 )}\end{array}$ & $\begin{array}{c}\text { ELG** } \\
(\mathbf{n = 6 5 9 )}\end{array}$ & $\boldsymbol{p}$ value \\
\hline Indwelling stent/catheter & $177(72.5)$ & $446(67.7)$ & 0.043 \\
Double-J stent & $136(55.7)$ & $355(53.9)$ & 0.063 \\
Failure & & & \\
$\quad$ Initial stone-free rate & $192(78.7)$ & $586(88.9)$ & 0.031 \\
$\quad$ Overall stone-free rate & $221(90.6)$ & $605(91.8)$ & 0.238 \\
Complications & $32(13.1)$ & $95(14.4)$ & 0.044 \\
$\quad$ Pain requiring analgesia & $7(2.9)$ & $26(3.9)$ & 0.053 \\
$\quad$ Hematuria >72 hours & $4(1.6)$ & $17(2.6)$ & 0.031 \\
$\quad$ UTI & $4(1.6)$ & $15(2.3)$ & 0.042 \\
-Ureteric injuries: & $17(7)$ & $37(5.6)$ & 0.057 \\
$\quad$ Perforation & $7(2.9)$ & $21(3.2)$ & 0.038 \\
Avulsion & $1(0.4)$ & $0(0)$ & 0.029 \\
False passage & $7(2.9)$ & $15(2.3)$ & 0.060 \\
$\quad$ Stricture & $2(0.8)$ & $1(0.1)$ & 0.033
\end{tabular}

Values are presented as number (\%); $p<0.05$ is significant. *Emergency group underwent ureteroscopy within 24 hours of admission to an emergency room; **Elective group underwent ureteroscopy more than 24 hours of admission to an emergency room.

UTI: urinary tract infection; EMG: emergency group; ELG: elective group.

( $p=0.038)$. Most of these perforations, in both groups, were minor and managed with temporary double-J stents. There was only 1 major perforation in the EMG group which was treated with the combined access (ante and retrograde) approach for intubation. One case of ureteral perforation as a result of elective URS was repaired by open surgery with spatulated end-end anastomosis and double-J stent. False passage, with clinically irrelevant consequences, was the second most common cause of iatrogenic ureteric injury. It was noted in more EMG cases ( 2.9 vs. $2.3 \%, p=0.06)$. One case of avulsion ( $0.4 \%$ ) by Dormia basket and 2 cases of strictures requiring operative reconstruction were reported in the EMG group compared to 1 case of ureteric stricture among ELG ones (0.8 vs. $0.1 \%$ ).

\section{Discussion}

Treatment of ureteric stones has gone through many changes since the introduction of in-situ extracorporeal shock wave lithotripsy (SWL). Stone-free rates have been calculated in many clinical trials. Superiority was variable depending on many factors which include stone-, technique- and staffrelated factors. Overall better outcome was reported using URS. ${ }^{13,14}$ Stone-free rates of $81 \%, 86 \%$ and $94 \%$ for proximal, middle and distal ureteric stones, respectively, have been reported. ${ }^{15}$ Comparing various treatment modalities is difficult, but when favourable end points are highlighted, namely stone-free rate and safety, URS appears to be more effective. ${ }^{16-18}$ With marked technology advances in instrumentation and energy sources, endo-luminal retrograde ureteric (and intra-renal) stone clearance is becoming more recognized..$^{19-21}$

Our stone-free rates calculated over 4 weeks $(91.5 \%)$ is comparable to international rates. ${ }^{15}$ Better results with 
URS approaching $100 \%$ stone-free rates have been reported. ${ }^{22}$ Lower success rates in our series of $91.5 \%$ may be attributed to the mechanical energy source, rigid URS and shorter follow-up period. The overall morbidity is similar to related publications, about $13.7 \%{ }^{20,23,24}$ Most of these complications, however, were minor and corrected without added risks and/or secondary anesthesia. Significant Grade IIIb complications, after Clavien, ${ }^{12}$ were only noted in 6 iatrogenic ureteric injuries, giving a rate of $0.7 \%$. With these higher rates of success and safety, URS has emerged as a more favourable option in stone clearance.

Most patients had ureteric stents during the earlier phase of our study. This practice was routine..$^{20,25,26}$ Stenting/catheter placement has been remarkably reduced in our current practice and left to the discretion of the treating urologist. It is considered optional as advised by current international guidelines. ${ }^{3}$

Emergency URS reduces the need for medications (analgesics, anti-inflammatory) and prolonged hospitalization. This is achieved at a lower cost, ${ }^{27}$ with comparable success and safety. Emergency URS is recommended, on the other hand, at the expense of discontinuing conservative (medical) treatment, admission, anesthesia and abandoning the expectant approach for spontaneous stone passage. Medical, emergency or elective URS is best advised after proper patient counselling. ${ }^{28}$

The concept of emergency definitive stone clearance is attractive and cost-effective. This remarkable trend towards a one-stage definitive solution reduces patient's suffering and maintains productivity. Three published retrospective studies have clearly shown the value of emergency URS stone treatment (Table 3). 8,29,30 Satisfactory stone-free rates and acceptable morbidity were reported. One study dealt with patients with acute renal failure and revealed excellent anatomical clearance and functional recovery. ${ }^{30}$ Comparable hospital stay was also reported. Our team's previous review was more elaborate and included significantly more patients. ${ }^{8}$ In all 3 articles, better results were achieved in stones $>1 \mathrm{~cm}$ in size and more distally located.

In recent 2 controlled trials comparing emergency and elective URS stone treatment, the difference was not statistically significant in terms of efficacy and safety. Both studies have strongly recommended the emergency URS approach. ${ }^{28,31}$ Failure rates ranged from $6.5 \%$ to $10 \%$ in both studies. The use of stents was also popular. Guercio and colleagues interestingly showed that neither stone size nor location carried any prognostic significance. Higher use of double-J stents was reported in the elective surgery group (80\% vs. $19.4 \%){ }^{31}$

Our study has its limitations. It is retrospective and not controlled. It did not take into account the variations in technology and staff. The study also did not consider cost, which is an important social and political factor. The study,
Table 3. Emergency ureteroscopic studies

$\begin{array}{lccc}\text { Study } & \begin{array}{c}\text { Osorio et al. }{ }^{29} \\ \text { Design }\end{array} & \begin{array}{c}\text { Yang et al. }{ }^{30} \\ \text { Retrospective }\end{array} & \begin{array}{c}\text { Al-Ghazo et } \\ \text { al. }^{8}\end{array} \\ \text { No. patients } & 144 & 49 & 244 \\ \text { Age (yrs) } & 49.6 & - & 45.6 \\ \text { Average size } & 9.1 \mathrm{~mm} & 14.8 \mathrm{~mm} & 9.2 \mathrm{~mm} \\ \text { Distal } & 90.30 \% & - & 61.1 \\ \text { Proximal } & 9.70 \% & - & 38.9 \\ \text { Energy } & \text { Pneumatic } & \text { Ho:YAG } & \text { Pneumatic } \\ \text { Catheter/stent \% } & 100 & - & 72.5 \\ \text { Operative time } & - & 35 \text { min } & 69 \text { min } \\ \text { Mean hospital } & 2.5 \text { days } & - & 1.9 \text { days } \\ \text { stay } & 1 \text { month } & 3 \text { months } & 4 \text { weeks } \\ \text { Follow-up } & 92.4 & 91.8 & 90.6 \\ \text { Overall SFR } & 4.2 & 8.2 & 13.1 \\ \text { Morbidity \% } & - & \text { all ARF } & - \\ \text { Remarks } & & & \end{array}$

however, has reasonable strength in its large sample sizes and comparative analysis. In the end, we feel that the emergency approach will stand the test of time. For this reason, our group has started a properly controlled study considering both the statistical design along with all other interdependent variables, namely patients, stone, disease, institution/ technology and staff characteristics.

\section{Conclusion}

The current study has shown that emergency URS treatment (within 24 hours of admission to emergency department) for obstructing ureteric stones is effective and safe. Compared to elective URS, it reduces suffering and speeds recovery. In the absence of established best practices, emergency URS should be seriously considered as the first treatment option in these clinical situations. Larger scale and more controlled multi-institutional collaborative studies would be useful. Patient counselling and well-informed decision-making are highly recommended.

Competing interests: None declared.

This paper has been peer-reviewed.

\section{References}

1. Zhang MY, Ding ST, Lü JJ, et al. Comparison of tamsulosin with extracorporeal shock wave lithotripsy in treating distal ureteral stones. Chin Med J 2009;122:798-801.

2. Preminger G, Tiselius H, Assimos D, et al. Guideline for the Management of Ureteral Calculi. Eur Urol 2007;52:1610-31. http://dx.doi.org/10.1016/i.eururo.2007.09.039

3. Türk C, Knoll T, Petrik A, et al. Guidelines on urolithiasis (2011) European Association of Urology (EAU). http://www.uroweb.org/gls/pdf/18_Urolithiasis.pdf. Accessed June 10, 2013. 
Matani et al.

4. Teichman J. Acute Renal Colic from Ureteral Calculus. N Engl J Med 2004;350:684-93. http://dx.doi.org/10.1056/NEJMcp030813

5. Bader M, Eisner B, Porpiglia F, et al. Contemporary management of ureteral stones. Eur Urol 2012;61:764 72. http://dx.doi.org/10.1016/i.eururo.2012.01.009

6. Seitz C, Tanovic E, Kikic Z, et al. Rapid extracorporeal shock wave lithotripsy for proximal ureteral calculi in colic versus noncolic patients. Eur Urol 2007;52:1223. http://dx.doi.org/10.1016/j.eururo.2007.02.001

7. Anagnostou T, Tolley D. Management of ureteric stones. Eur Urol 2004;45:714-21. http://dx.doi. org/10.1016/j.eururo.2003.10.018

8. Al-Ghazo M, Ghalayini I, A-Azab R, et al. Emergency ureteroscopic lithotripsy in acute renal colic caused by ureteral calculi: a retrospective study. Urol Res 2011;39:497-501. htrtp://dx.doi.org/10.1007/s00240-011-0381-y

9. Elashry OM, Elgamasy AK, Sabaa MA, et al. Ureteroscopic management of lower ureteric calculi: a 15-year singlecentre experience. BJU Int 2008;102:1010-7. http://dx.doi.org/10.1111/j.1464-410X.2008.07747.x

10. Hollenback BK, Schuster TG, Faerber GJ, et al. Comparison of outcomes of ureteroscopy for ureteral calculi located above and below the pelvic brim. Urology 2001;58:351-6. httrp://dx.doi.org/10.1016/50090-4295(01)01266-3

11. Jordan Population and Family Health Survey 2009. Department of Statistics, Amman, Jordan. ICF Macro Calverton, Maryland, May, 2010.

12. Clavien $\mathrm{P}$, Barkun J, Oliveira $\mathrm{M}$, et al. The Clavien-Dindo Classification of Surgical Complications: Fiveyear Experience. Ann Surg 2009;250:187-96. http://dx.doi.org/10.1097/SLA.0b013e3181b13ca2

13. Phipps S, Tolley DA, Young JG, et al. The management of ureteric stones. Ann R Coll Surg Engl 2010;92:368-72. http://dx.doi.org/10.1308/003588410X12664192075693

14. Autorino R, Osorio L, Lima EA. Rapid extracorporeal shock wave lithotripsy for proximal ureteral calculi in colic versus noncolic patients. Eur Urol 2007;52:1264-5. http://dx.doi.org/10.1016/i.eururo.2007.04.040

15. Nabi G, Downey P, Keeley F, et al. Extra-corporeal shock wave lithotripsy (ESWL) versus ureteroscopic management for ureteric calculi. Cochrane Database Syst Rev 2007;CD006029.

16. Kijvikai K, Haleblian GE, Preminger GM, et al. Shock wave lithotripsy or ureteroscopy for the management of proximal ureteral calculi: an old discussion revisited. J Urol 2007;178:1157-63. http://dx.doi.org/10.1016/i.juro.2007.05.132

17. Lam JS, Greene TD, Gupta M. Treatment of proximal ureteral calculi: holmium:YAG laser ureterolithotripsy versus extracorporeal shock wave lithotripsy. J Urol 2002;167:1972-6. http://dx.doi.org/10.1016/ S0022-5347(05)65065-3

18. Wu CF, Shee JJ, Lin WY, et al. Comparison between extracorporeal shock wave lithotripsy and semirigid ureterorenoscope with holmium:YAG laser lithotripsy for treating large proximal ureteral stones. I Urol 2004;172:1899-902. http://dx.doi.org/10.1097/01.ju.0000142848.43880.b3

19. Galvin D, Pearle M. The contemporary management of renal and ureteric calculi. BJU Int 2006:98:123888. http://dx.doi.org/10.1111/i.1464-410X.2006.06514.x
20. Elashry 0, Elgamasy $A$, Sabaa $M$, et al. Ureteroscopic management of lower ureteric calculi: a 15 -year singlecentre experience. BJU Int 2008;10:1010-7. http://dx.doi.org/10.1111/j.1464-410X.2008.07747.x

21. Cocuzza M, Colombo JR, Ganpule A, et al. Combined retrograde flexible ureteroscopic lithotripsy with holmium YAG laser for renal calculi associated with ipsilateral ureteral stones. J Endourol 2009;23:253-7. http://dx.doi.org/10.1089/end.2008.0368

22. Sofer M, Watterson JD, Wollin TA, et al. Holmium: YAG laser lithotripsy for upper urinary tract calculi in 598 patients. J Urol 2002;167:31-4. http://dx.doi.org/10.1016/S0022-5347(05)65376-1

23. Schuster $T G$, Hollenbeck BK, Faerber $G J$, et al. Complications of ureteroscopy: analysis of predictive factors. J Urol 2001;166:538-40. http://dx.doi.org/10.1016/S0022-5347(05)65978-2

24. Johnson DB, Pearle MS. Complications of ureteroscopy. Urol Clin North Am 2004;31:157-71. http://dx.doi.org/10.1016/S0094-0143(03)00089-2

25. Srivastava A, Gupta R, Kumar A, et al. Routine stenting after ureteroscopy for distal ureteral calculi is unnecessary: results of a randomized controlled trial. J Endourol 2003;17:871-4. http://dx.doi.org/10.1089/089277903772036172

26. Chen YT, Chen J, Wong WY, et al. Is ureteral stenting necessary after uncomplicated ureteroscopic lithotripsy? A prospective, randomized controlled trial. J Urol 2002;167:1977-80. http://dx.doi.org/10.1016/S0022-5347(05)65066-5

27. Youn J, Kim S, Yu J, et al. Efficacy and Safety of Emergency Ureteroscopic Management of Ureteral Calculi. Korean J Urol 2012;53:632-5. http://dx.doi.org/10.4111/kju.2012.53.9.632

28. Sarica $\mathrm{K}$, Tanriverdi 0 , Aydin $\mathrm{M}$, et al. Emergency ureteroscopic removal of ureteral calculi after first colic attack: is there any advantage? Urology 2011;78:516-20. http://dx.doi.org/10.1016/j.urology.2011.01.070

29. Osorio L, Lima E, Soares J, et al. Emergency Ureteroscopic Management of Ureteral Stones: Why Not? Urology 2007;69:27-31. http://dx.doi.org/10.1016/i.urology.2006.08.1116

30. Yang S, Qian $H$, Song $C$, et al. Emergency ureteroscopic treatment for upper urinary tract calculi obstruction associated with acute renal failure: feasible or not? J Endourol 2010;24:1721-4. http://dx.doi.org/10.1089/end.2009.0420

31. Guercio S, Ambu A, Mangione F, et al. Randomized prospective trial comparing immediate versus delayed ureteroscopy for patients with ureteral calculi and normal renal function who present to the emergency department. J Endourol 2011;25:1137-41. http://dx.doi.org/10.1089/end.2010.0554

Correspondence: Dr. Yousef S. Matani, Associate Professor of Urology, Um AL-sommaq Post Office, P.0. Box 2171, 11821 Amman, Jordan; ymatani@gmail.com 